\section{Dubai \\ Medical Journal}

\title{
Retraction Statement
}

\author{
Paper by AlJassmi et al. [Dubai Med J. 2019;2:50-53, \\ DOI: $10.1159 / 000500805]$
}

The article entitled "Shwachman-Diamond Syndrome: A Case Report and Literature Review" [Dubai Med J. 2019;2:50-53] by AlJassmi AM, Rana AN, Humad H, Madasu A, and Khan SS has been retracted by the Publisher and Editor because, contrary to the Statement of Ethics in the manuscript, whilst consent was obtained from the patient's parents for medical records to be reviewed and used for scientific purposes while maintaining patient confidentiality, informed consent for the publication of the case report where complete anonymity cannot be guaranteed was not obtained. The article is no longer available online in order to protect patient confidentiality. 